\title{
Prescribing constraints in primary care: false economy or necessary husbandry?
}

\author{
Sarah Jarvis
}

\begin{abstract}
Addressing high rates of unwanted pregnancy
Nobody working in reproductive health doubts that the UK has a problem - or rather, several problems. We have the highest teenage pregnancy rate in Western Europe, with levels twice those of Germany, three times those of France and six times those of Holland. ${ }^{1}$ In real terms, this translates into 90000 conceptions a year to teenagers in the UK, of whom $40 \%$ have terminations of pregnancy and $60 \%$ continue with the pregnancy. Of those becoming mothers in their teenage years, $90 \%$ are unmarried and at least $50 \%$ are not in a relationship. ${ }^{1}$ Nor is the situation improving. Despite an overall trend towards later childbearing, the proportions of teenagers getting pregnant in the UK have continued to rise since the late 1970s. In 1999,45 in $100015-17$-year-olds and 68 in $100015-19$ year-olds conceived. ${ }^{2}$ Between 2001 and 2002, there was a further $8.7 \%$ increase in the proportion of under-18s becoming pregnant - an absolute increase of $800 .^{3}$
\end{abstract}

\section{Emergency contraception and unwanted pregnancy} Of the $30 \%$ of UK women having sex under the age of 16 years, about half do not use contraception at least on the first occasion they have sex, and under-16s are less likely to use regular contraception than older age groups. Likewise, those from lower socioeconomic groups are less likely to use contraception than those from higher groups. ${ }^{2}$

But unprotected sexual intercourse is not an issue only for the under-16s or the uneducated: 76\% of 16-24-yearolds in continuing education have either had sex without contraception or have had a contraception failure. Of these, $72 \%$ had used emergency hormonal contraception (EC) on at least one occasion but only $37 \%$ had used it on every occasion of unprotected intercourse. ${ }^{4}$

Nor has the availability of EC from pharmacies had a significant impact on patterns of contraception. The overall proportion of women using EC remained constant at about $8 \%$ before and after the introduction of EC from pharmacists without prescription in 2001. There has been no significant change at this time in the proportion of women using more reliable methods of contraception, such as the oral contraceptive pill, or in the proportion of women using EC more than once during a year. ${ }^{5}$

\section{Provision of reliable contraception: barriers and challenges}

There is no doubt that providing reliable contraception, especially to the under-16s, is a major challenge. The Social Exclusion Unit of the Department of Health, which in 1999 published a report on tackling teenage pregnancies, highlighted a culture of mixed messages as one of the major reasons. ${ }^{2}$ Society and youth culture bombard teenagers with sexually explicit messages, and many teenagers feel intense peer pressure to have sex - but real

J Fam Plann Reprod Health Care 2005; 31(4): 263-265

Richford Gate Medical Practice, London, UK

Sarah Jarvis, DRCOG, FRCGP, General Practitioner

Correspondence to: Dr Sarah Jarvis, Richford Gate Medical Practice, Richford Street, London W6 7HY, UK.

E-mail: sarah.jarvis@gp-E85016.nhs.uk or perceived anxieties about the medico-legal implications of prescribing contraception for the under-16s make health care professionals wary of providing full information, and teenagers suspicious about approaching those who might offer it. ${ }^{6}$

Other anxieties include confidentiality, which is a particular issue for young people registered with general practitioners (GPs) who look after the rest of their families. This may account for the rise in the percentage of girls aged 13-15 years who attended family planning clinics (FPCs), from nearly $5 \%$ in 1993-1994 to almost $10 \%$ in 2003-2004. ${ }^{2}$ This increase in FPC use, however, does not account for nearly everyone having intercourse. Among 15 -year-olds, $38 \%$ are sexually active but only $10 \%$ are using oral contraception, the most common method in the UK among all age groups. ${ }^{7}$ The falling age of first sexual activity - from 17 years in 1990 to 16 years in 2000, with 1 in 3 under-16s now sexually active ${ }^{3}-$ means that more and more sexually active females fall into the 'grey area' where anxiety about confidentiality is highest. ${ }^{6}$

Consequently, there is a tendency to turn to peers for advice on contraception, which makes it easy for myths about limitations and side effects of contraception to persist. Major anxieties, which may have a significant impact on compliance with reliable methods of contraception, include weight gain, fluid retention, breast tenderness, skin problems, loss of fertility following combined oral contraceptive (COC) or intrauterine device use, and increased risk of sexually transmitted infections (STIs). While newer forms of COC may not have a vastly better side effect profile than older versions, even small improvements in weight, acne and cycle control may improve compliance enough to reduce the likelihood of unwanted pregnancy. ${ }^{8}$

\section{Prescribing restraints and their implications for reproductive health}

There are numerous mechanisms by which local and national bodies can, and do, bring pressure to bear on prescribers to reduce their prescribing of more expensive medications. Many non-contraceptive drugs have now been assessed by the National Institute for Health and Clinical Excellence (NICE), which has recommended that they should not be used. In theory, NICE considers a wide variety of evidence including cost, cost-effectiveness and utility modelling for different groups in reaching its determination. In practice, however, potential savings that may impact significantly on cost-effectiveness seem often to be ignored if they work in favour of a more expensive alternative. The potential cost saving resulting from a reduction in breast cancer for patients with osteoporosis taking the selective oestrogen receptor modulator, raloxifene, which NICE did not take into account, is one of many examples. ${ }^{9}$

Technically, even national bodies such as NICE have no right to prevent qualified health care professionals from prescribing any medication for an indication for which it is licensed. Their guidelines are just that - guidelines, rather than protocols. In practice, however, their recommendations are being used by primary care organisations to implement draconian restrictions on prescribing, which have left many doctors in the community anxious about cost to the exclusion of the wider picture. 
Even if a doctor asserts their right to prescribe a drug not recommended by NICE, the Primary Care Trust or hospital trust can choose not to fund it. This has meant that, in practice, many expensive drugs (such as interferon beta) have essentially been banned, even though they have a licence in the UK. Factors such as these certainly contribute to the relatively low prescribing rates of new medications in the UK. ${ }^{10}$ It seems likely that it is only a matter of time before NICE turn their attention to the wider clinical area of contraception.

\section{Issues for FPCs}

Unfortunately, many FPCs have also had their right to prescribe a full range of contraceptives curtailed by local formularies. In primary care, most practice formularies offer guidelines that the GP can override if they feel there is a compelling reason to prescribe outwith their limits. For a FPC doctor, however, the restriction is total. If a contraceptive option (Yasmin ${ }^{\circledR}$, Evra ${ }^{\circledR}$ and Cerazette ${ }^{\circledR}$ have all been affected) is not on the FPC formulary, the clinic has only two choices: to prescribe an alternative that is on the formulary or to send the patient to a GP for a prescription. Both of these options reduce choice for the patient, and may decrease the likelihood of compliance with reliable contraception.

\section{Particular issues for primary care}

While most GPs do not have prescribing formularies that completely prevent them from prescribing specific contraceptive preparations, they too are subject to huge pressure to keep prescribing costs down. In recent years, GPs have been subjected to a barrage of national and local initiatives, reinforced by national guidance from NICE and local indicative prescribing schemes. Prescribing advisors regularly visit practices whose prescribing budgets for a particular clinical area fall more than $25 \%$ outside the average for the area, and such visits are often perceived to have a punitive feel.

While individual methods of contraception have not, as yet, been subject to adverse recommendations by NICE, local guidance often has a very narrow remit, concentrating on cost or direct cost-effectiveness. ${ }^{11-13}$ Add to this anxiety about safety of contraception (such as the venous thromboembolism scare generated by the Committee on Safety of Medicines warnings on third-generation pills in 1995, and depot contraceptive injections and osteoporosis last year ${ }^{14}$ ) and it is hardly surprising that primary health care professionals - and, to an extent, family planning doctors - are tempted to prescribe conservatively. In fact, the UK has one of the most conservative prescribing patterns in the Western world across all clinical areas, with one of the lowest uptakes per head of new medications relative to comparator countries. ${ }^{10}$ In addition, of course, GPs are not allowed to prescribe condoms, despite their remit to encourage safer sex and reduce the incidence of STIs.

\section{Contraception and the nation: the way forward}

The rate of unwanted pregnancy in the UK is so high that we must use all the measures within our power to reduce it.
Increasing public awareness about available services, as well as better education on confidentiality and contraception for under-16s, are important weapons in this war. ${ }^{6}$ So too are the wider issues such as societal attitudes towards parenthood. ${ }^{2}$

Offering a broader and more comprehensive range of contraceptive services, and considering the indirect potential cost savings as well as the direct costs associated with prescribing some of the newer medications, should be part of this strategy. Until the Government, national bodies such as NICE, and local prescribing advisors in particular stop concentrating on short-term costs to the exclusion of the wider picture, we will not give the women of this country the service they need.

Statements on funding and competing interests

Funding. None identified.

Competing interests. None identified.

References

1 http://www.socialexclusion.gov.uk/downloaddoc.asp?id=69 [Accessed 8 August 2005].

2 http://www.statistics.gov.uk/StatBase/ssdataset.asp?vlnk=4985\& More $=Y$ [Accessed 8 August 2005]

3 Paton D. The economics of family planning and underage conceptions. J Health Econ 2002; 21: 27-45.

4 Free C. Contraceptive risk and compensatory behaviour in young people in education post-16 years: a cross-sectional study. J Fam Plann Reprod Health Care 2004: 3: 91-94.

5 Marston C, Meltzer H, Majeed H. Impact on contraceptive practice of making emergency hormonal contraception available over the counter in Great Britain: repeated cross sectional surveys. BMJ 11 July 2005; doi:10.1136/bmj.38519.440266.8F

6 Krishnamoorthy N, Ekins-Daukes S, Simpson CR, Milne RM, Helms PJ, McLay JS. Adolescent use of the combined oral contraceptive pill. A retrospective observational study. Arch Dis Child 2005; 0: 200405917 [Epub 26 April 2005].

7 Dawe F, Meltzer H. Contraception and Sexual Health, 2002. London, UK: Office for National Statistics, 2003. http://www.statistics. gov.uk/downloads/theme_health/Contracepts2002.pdf [Accessed 11 March 2005].

8 Muhn P, Krattenmacher R, Beier S, Elger W, Schillinger E. Drosperidone, a novel progestogen with antimineralocorticod and antiandrogenic activity. Pharmacological characterization in animal models. Contraception 1995; 51: 99-110.

9 National Institute for Clinical Excellence. Bisphosphonates (alendronate, etidronate, risedronate), selective oestrogen receptor modulators (raloxifene) and parathyroid hormone (teriparatide) for the secondary prevention of osteoporotic fragility fractures in postmenopausal women. Technology Appraisal 87, January 2005.

10 Pharmaceutical Industry Competitiveness Task Force. Competitiveness and Performance Indicators 2004. December 2004. http://www.advisorybodies.doh.gov.uk/pictf/2004Indicators.pdf [Accessed 8 August 2005].

11 Gallo MF, Grimes DA, Schulz KF. Skin patch and vaginal ring versus combined oral contraceptives for contraception. Cochrane Database Syst Rev 2003(1): CD003552. http://www.update-software.com/ Abstracts/ab003552.htm [Accessed 8 August 2005].

12 NHS Northern and Yorkshire Regional Drug and Therapeutics Centre. New Drug Evaluation No. 53: Yasmin ${ }^{\circledR}$ January 2003. http://www.nyrdtc.nhs.uk/docs/nde/NDE 53.pdf [Accessed 8 August 2005].

13 NHS Northern and Yorkshire Regional Drug and Therapeutics Centre. New Drug Evaluation No. 56: Cerazette ${ }^{\circledR}$. May 2003. http://www.nyrdtc.nhs.uk/docs/nde/NDE_56.pdf [Accessed 8 August 2005].

14 http://medicines.mhra.gov.uk/ourwork/monitorsafequalmed/ safetymessages/depo-provera_letterhealthprofs_181104.pdf.

\section{Visit the Faculty Website at: www.ffprhc.org.uk}

